DOI 10.37882/2223-2982.2020.08-2.11

\title{
ВОПРОСЫ ОРГАНИЗАЦИИ ПРАКТИКО-ОРИЕНТИРОВАННОГО ОБУЧЕНИЯ В СФЕРЕ ИНФОКОММУНИКАЦИОННЫХ ТЕХНОЛОГИЙ
}

\section{ISSUES OF ORGANIZATION OF PRACTICE- ORIENTED TRAINING IN THE SPHERE OF INFOCOMMUNICATION TECHNOLOGIES}

\section{B. Karev \\ V. Prokoptsev \\ N. Prokoptseva}

Summary: The article presents an analysis of current approaches to the organization of practice-oriented learning, identifies modern organizational and structural forms and means of their implementation, identifies the contradictions of educational technologies, practical orientation associated with their real implementation, and formulates possible ways to resolve them.

Keywords: practice-oriented learning, educational technologies, vocational education, distance education, industrial and pre-diploma practice, contact work, independent work of students.

\section{Карев Борис Анатольевич}

д.n.н, професссор, член-корреспондент РАО, Российская академия образования (2. Москва)

karevdok.27@mail.ru

Прокопцев Владимир Олегович

к.т.н., доцент, Хабаровский институт

инфокоммуникаций

azp_prokoptsev@mail.ru

Прокопцева Надежда Владимировна

к.п.н., доцент, Дальневосточный юридический институт

МВД России (2. Хабаровск)

dfokhvru27@gmail.com

Аннотация: В статье представлен анализ актуальных подходов к организации практико-ориентированного обучения, определены современные организационно-структурные формы и средства их реализации, выявлены противоречия образовательных технологий практической направленности, связанные с их реальным воплощением, а также сформулированы возможные пути их разрешения.

Ключевые слова: практико-ориентированное обучение, образовательные технологии, профессиональное образование, дистанционное образование, производственная и преддипломная практики, контактная работа, самостоятельная работа обучающихся.
A нализ содержания профессионального образования показал, что все большую значимость приобретают практико-ориентированные формы организации учебного процесса. Выделяют как правило два основных подхода к практико-ориентированному обучению в системе высшего образования. Первый направлен на взаимодействие обучающегося с предполагаемой профессиональной средой через учебную, производственную и преддипломную практики. Второй подход предполагает использование образовательных технологий, предоставляющих возможность предать практико-ориентированную направленность всем аудиторным занятиям в ходе освоения образовательных программ. Учитывая современный уровень развития телекоммуникационных систем в сфере образования практико-ориентированное обучение возможно и целесообразно при комплексном применении обозначенных подходов $[1,5]$.

Рассмотрим подробнее практико-ориентированное обучение в части производственной и преддипломной практик на примере подготовки специалистов в сфере инфокоммуникационных технологий. В докладах Правительства Российской Федерации о реализации госу- дарственной политики в сфере образования регулярно отмечается внедрение практико-ориентированных подходов в реализации образовательных программ на разных уровнях образования. В сфере высшего образования одним из ключевых моментов указываются мероприятия по взаимодействию с ведущими работодателями и расширению их участия в образовательном процессе [3].

Таким образом, вне зависимости от профиля подготовки, достаточно обоснованным является необходимость согласования содержания образовательных программ на предмет их актуальности и востребованности, особенно в части их практической реализации, с предприятиями, принимающими обучающихся на практику, равно как и с потенциальным работодателем.

Значимость производственной практики как одного из аспектов профессионального образования объясняется возможностью обучающихся приобрести опыт профессиональной деятельности в статусе практикантов, помощников, ассистентов, стажеров и так далее. На данном этапе перед обучающимися должен стоять ряд задач: 
- изучение технологии монтажа и обслуживания направляющих систем электросвязи (проводных, беспроводных);

- изучение технологического оборудования, используемого на предприятии или тестируемого предприятием;

- освоение методики контроля и измерения параметров оборудования на существующих линиях [2].

Для более полного погружения практикантов в производственный процесс предприятия применяют такой метод обучения как моделирование конкретной рабочей ситуации с целью приобретения опыта решения технологических задач. Конкретный вариант специально подобранных условий - апробированная модель производственной реальности позволяет, например, скорректировать задания для практических занятий или курсового проектирования по профильным дисциплинам, с целью повышения степени практикоориентированности обучения [4].

Решение конкретной производственной задачи должно происходить под руководством наставника из коллектива технических специалистов организации. Решение задачи должно быть подробно алгоритмизировано, с представлением необходимых пояснений практиканту. Проблема уникальности производственных ситуаций (задач) решается составлением унифицированного алгоритма, отражающего основные, неизменные параметры решения задач.

Наглядный пример профессионального выполнения действий при разборе ситуаций обладает, помимо обучающего, мощным воспитательным и развивающим потенциалом, так как позволяет не только эффективно усвоить посредством практики информационный компонент определенной профессиональной области, но и сформировать востребованные обществом качества личности, такие как внимательность, усердие, аккуратность, ответственность и так далее. Развитие личности обучающегося при таком формате освоения учебного материала происходит за счет того, что им приобретается опыт решения производственных вопросов, что в свою очередь способствует усилению интереса к профессии, вырабатывает мотивацию к осознанному творчеству.

Однако при организации производственной и преддипломной практик на предприятиях связи существует ряд нюансов, которые снижают эффективность обучения студентов. Рассмотрим наиболее явные аспекты, скорректировать которые возможно и необходимо совместными усилиями образовательных организаций и профильных предприятий.
Несвоевременное согласование образовательной организацией всех разделов задания на практику с работодателем и (или) отсутствие согласования как такового является причиной следующих проблем. Вопервых, программа практики, как правило, составляется унифицировано для всех студентов, направляемых на предприятия. Недостаток такого подхода в том, что если предприятие крупное, то специфика отделов, в которые гипотетически распределяются студенты, может быть различна. Поэтому и программа практики должна быть составлена с учетом особенностей конкретного направления работы отдела (подразделения). Во-вторых, указанные преподавателем разделы в индивидуальном задании на практику зачастую невозможно изучить, поскольку некоторые элементы оборудования заменены, произошла смена ПО, изменилась модель обслуживания сети и (или) методика измерений. В этой связи, перечень индивидуальных заданий на практику для обучающихся целесообразно ежегодно согласовывать с работодателем с учетом внедрения нового оборудования, технологий и программного обеспечения на профильном предприятии.

Кроме этого, для эффективного обучения студентов на практике образовательной организации следует предварительно согласовывать ПО, с которым студентам предстоит работать на предприятии. Знание студентами характеристик аппаратуры, используемой на предприятии, её спецификаций и различных схем применения еще до начала практики позволяет самостоятельно или при поддержке преподавателя получить навыки работы с конкретным ПО, при условии, что данное ПО можно развернуть на имеющихся вычислительных мощностях учебного заведения. Таким образом, предприятия могут сократить время на ознакомительную часть практики, и значительно раньше приступить к основной её части, а именно к формированию определенных программой практики компетенций.

В настоящее время недостаточно проработан механизм компенсации специалисту от предприятия его занятости со студентами на производственной и преддипломной практиках. Отсутствие оплаты труда за осуществление функций руководителя практики от предприятия на сегодня является скорее правилом, чем исключением. При отсутствии вознаграждения, сотрудники предприятий, задействованные в работе со студентами, имеют низкую мотивацию к выполнению своих обязанностей как наставники.

Ряд организаций имеет возможность принимать студентов на так называемую «оплачиваемую» производственную и преддипломную практики. Другими словами, на период практики предприятие вводит в штат оплачиваемую должность, на которую принимают обу- 
чающегося. Таким образом у студента появляется стимул качественно выполнять задачи, поставленные ответственными за практику лицами. У работодателя в свою очередь появляется инструмент управления новым сотрудником. Такой подход устраивает и студента, и работодателя, и учебное заведение. В наибольшем «плюсе» оказывается студент, поскольку кроме приобретения профессиональных знаний, умений и навыков, опыта работы в коллективе, возможности скорректировать ранее выбранную тему ВКР (если он проходит преддипломную практику) с учетом специфики организации, консультироваться с профильными специалистами этого же предприятия и собрать необходимую для ВКР информацию, он получает зарплату [4].

Некоторые предприятия отказывают образовательным учреждениям в принятии на практику студентов по причине того, что в программу подготовки бакалавров не включено освоение специализированного программного обеспечения, например, графических программ, с которыми работают проектные отделы (AutoCAD, KOMПАС, nanoCAD и ряд других). Сложность для образовательной организации состоит в том, что большинство программ платные, стоимость которых высока, а использование демо-версий программ зачастую не позволяет в полной мере оценить функционал (получить навыки работы). Тратить время на обучение студентов работе с программным обеспечением в период практики организации не готовы - им требуются уже подготовленные кадры.

Рассмотрим подробнее особенности второго подхода к организации практико-ориентированного обучения, сущность которого заключается в обеспечивании напрямую или косвенно связи теоретической части содержания дисциплины с профессиональной областью будущих специалистов, вне зависимости от конкретной темы учебного курса и способа организации контактной и самостоятельной работы (лекции, семинары, консультации, выполнение письменных работ и так далее) [5].

Рассмотрение различных классификаций практикоориентированных образовательных технологий, а также особенностей их применения является предметом отдельного изучения. В нашей статье мы приведем в качестве примера некоторые формы организации образовательного процесса, наиболее востребованные и действенные в настоящее время.

В силу сложившейся в стране ситуации, актуальным стало дистанционное образование. Проведение лекций, практических занятий и тому подобного с использованием видеосвязи и мессенджеров уже не является уникальным явлением. Обучающиеся достаточно быстро адаптировались к новому формату взаимодействия, что явно можно признать положительной особенностью дистанционной формы организации учебного процесса. Однако отрицательной чертой такого вида образования является резкий спад качества усвоения учебного материала, по причине снижения количественно-качественных показателей самостоятельной работы обучающихся, которая, стоит отметить, превалирует при сетевой форме реализации образовательных программ.

Одним из способов повышения степени формирования компетенций, определенных программными документами образовательных организаций, а также увеличение мотивации к изучаемому материалу, и как следствие будущей профессии, является привлечение студентов всех курсов к участию в онлайн-конференциях и семинарах, имеющих профильное направление. Предполагаемый эффект от участия в таких мероприятиях:

- обучающиеся узнают о современных тенденциях в выбранной ими профессиональной области;

- возможность узкопрофильного самоопределения - корректировка траектории индивидуального профессионального развития;

- возможность послушать доклады профильных специалистов, которые имеют большой опыт работы и могут конкретными примерами пояснить производственные процессы на предприятии.

- имеют возможность задавать вопросы по заинтересовавшим их направлениям, например, в чатах.

Участие в таких мероприятиях зачастую бесплатное, регистрация не вызывает сложностей, а эффект от участия существенен.

Онлайн-семинары для обучающихся можно проводить и с участием представителей потенциальных работодателей, заранее определив тему выступления. Таким образом в образовательный процесс включаются практические работники с опытом работы по профильному направлению, а не только профессорско-преподавательский состав. Такое взаимодействие полезно не только студентам, но и педагогическим работникам профильных дисциплин.

Анализ нормативно-правовых документов в части профессионального образования, а также изучение основных подходов к организации практико-ориентированного обучения позволяет определить современные тенденции в образовании практической направленности, трудности с их организационно-структурной реализацией - недостатки методов, форм и средств практикоориентированного обучения, а также сформулировать возможные пути решение проблем, связанных с их реальным воплощением. 


\section{ЛИТЕРАТУРА}

1. Федеральный закон от 29 декабря 2012 г. N 273-Ф3 «06 образовании в Российской Федерации» Российская газета от 31 декабря 2012 г. № 5976.

2. Федеральный государственный образовательный стандарт высшего образования по специальности 11.03.02 Инфокоммуникационные технологии и системы связи (уровень специалитета) от 19 сентября 2017 г. № 930.

3. Доклад Правительства Российской Федерации Федеральному Собранию Российской Федерации о реализации государственной политики в сфере образования, Москва 2020

4. Вербицкий А.А. Проблемы проектно-контекстной подготовки специалиста / А.А. Вербицкий // Высшее образование сегодня. - 2015. - № 4. - С. 2-8.

5. Мамыченко С.А. Практико-ориентированная модель обучения студентов в учебном процессе современного вуза / С.А. Мамыченко // Бизнес-образование в экономике знаний. - 2017. - № 2 - с. 92-98.

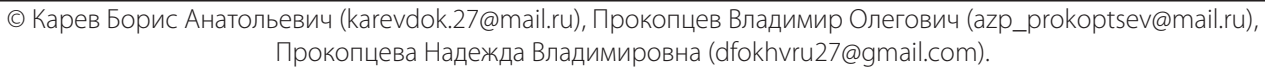

Журнал «Современная наука: актуальные проблемы теории и практики»

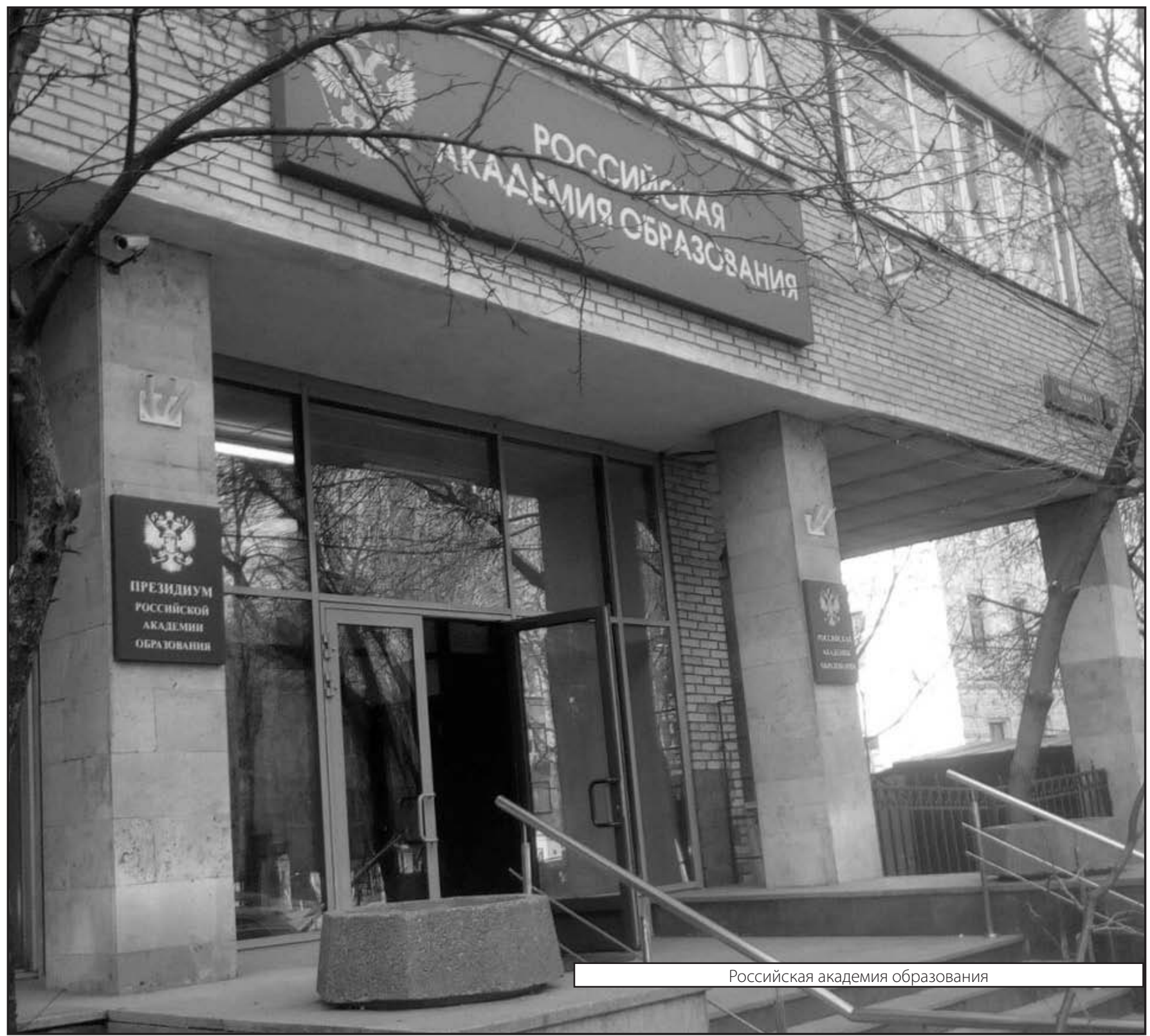

